\title{
Breast Cancers with Ocular Metastases are Early Onset, Non-Familial and Non-BRCA1/BRCA2 Tumours
}

\author{
Katarzyna Królewska ${ }^{1,2}$, Anna Jakubowska², Stanisław Zajączek² \\ 'Department of Ophthalmology; '2Department of Genetics and Pathology - International Hereditary Cancer Center, Pomeranian Medical University, Szczecin, Poland
}

Corresponding author: Stanisław Zajaczek, Department of Genetics and Pathology - International Hereditary Cancer Center, Pomeranian Medical University, Połabska 4, 70-115 Szczecin, Poland; e-mail: stazaj@polbox.com

Submitted: 8 December 2003

Accepted: 22 December 2003

\section{Dear Sirs,}

Ocular metastases of solid tumors are very rare, but in most of them ( $\sim 45-70 \%$ of all detected ocular metastases) the primary site of origin is the breast [ 1 , 2]. Ocular metastases of breast cancer appear frequently without previous dissemination to organs even those in close proximity. Thus, occurrence of ocular metastases may be the characteristic feature of a special subgroup of breast cancers. Herein, we decided to analyse whether breast cancers with associated ocular metastases belong to a group of cancers constituting a specific part of a subset of breast cancer family syndromes.

We investigated a series of 15 breast cancer patients with ocular metastases, detected in 1998-2002 by ophthalmologists in Szczecin (10 of 15) and Poznań (5 of 15). The distinction between breast cancer metastases and primary ocular tumours was based on results of routine ophthalmological examination supported in most cases by angiography, ultrasonography, computer tomography and magnetic resonance imaging. Tumours were verified pathologically (aspiration biopsy or surgical section) in 3 cases. In all three cases the metastatic character of the tumour was confirmed. In all 15 cases, age at diagnosis and pedigree data on the occurrence of cancers among first and second degree relatives was collected. In 11 of 15 cases peripheral blood lymphocyte DNA for mutations analyses were available. A search for the most common Polish BRCA1 gene mutations (5382insC, C61G and 4153 delA) was performed as described by Górski et al (2000). This test can detect around 90\% of all BRCA1 mutation carriers in the Polish population [3]. The presence of BRCA2 mutations was also investigated by full sequencing of coding regions of this gene [4].

Familial aggregation of breast cancers (one, additional to the proband, breast cancer patient among first degree relatives) was found in only one family. No patient with BRCA1 constitutional mutation was identified. BRCA2 mutations (3562 A/G and 9079 G/A) were detected in two patients. The remaining 12 patients did not present with any other unusual characteristics apart from early disease onset. In 10 of 12 cases, breast cancers have been diagnosed under 51 years of age $(27,29,29,36,40,41,42,42,44$, 50). Only in the case of two patients cancers were diagnosed in other first degree relatives (pancreatic cancer diagnosed at the age of 58 and endometrial cancer diagnosed at the age of 68).

Histopathology was not verified in this set of breast cancer patients, but multifocal disease was reported in 3 of 10 non-familial, non-BRCA1/2 mutation early onset cases. Furthermore, only one of them was reported to be a lobular type; all others were diagnosed as ductal cancers.

Our observation has several limitations: the studied series is small, not all metastatic tumours have been verified histopathologically and more precise data about the pathologic and molecular features of breast cancers is required.

Nevertheless, this small study shows that the characteristic features of breast cancers with ocular metastases include early age at diagnosis and the lack of familial aggregation of breast cancers and of BRCA1 and BRCA2 constitutional mutations. 
The early onset of breast cancer in these cases suggests a genetic predisposition and given the low frequency of cancers among first degree relatives, this predisposition might be a gene defect with recessive inheritance, a "de novo" dominant mutation, a complex genetic inheritance that does not follow obvious Mendelian inheritance (or possibly even an X-linked mutation with expression in females only).

\section{References}

1. Shields CL, Shields JA, Gross NE, Schwartz GP and Lally SE. Survey of 520 eyes with uveal metastases. Ophthalmology 1997; 104: 1265-1276.

2. Bloch RS and Gartner S. The incidence of ocular metastatic carcinoma. Arch Ophthalmol 1971; 85: 673-675.

3. Górski B, Byrski T, Huzarski T, Jakubowska A, Menkiszak J, Gronwald J, Płużańska M, Bębenek M, Fischer-Maliszewska t, Grzybowska E, Narod SA and Lubiński J. Founder mutations in the BRCA1 gene in Polish families with breast-ovarian cancer. Am J Hum Genet 2000; 66: 1963-1968.

4. Jakubowska A, Scott R, Menkiszak J, Gronwald J, Byrski T, Huzarski T, Górski B, Cybulski C, Dębniak T, Kowalska E, Starzyńska T, Ławniczak M, Narod SA and Lubiński J. A high frequency of BRCA2 gene mutations in Polish families with ovarian and stomach cancer. Eur J Hum Genet 2003; 11: 955-958. 